\title{
Elastin and Collagen in the Fetal Sheep Lung. II. Relationship to Mechanical Properties of the Lung
}

\author{
JEAN-CIAUDE SCHELIENBERG. GRAHAM C. I.IGGINS. JOSEPH A. KITIIRMAN \\ AND ( HU-CHING H. I.EE

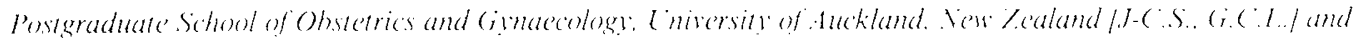

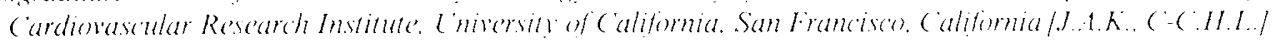

\begin{abstract}
ABSTRACI. The relationship between elastin and collagen concentration and indices of lung maturation was studied in the lungs of fetal sheep. Fetal sheep of 124 days gestation were infused for $84 \mathrm{~h}$ with cortisol, triiodothyronine, prolactin, or epidermal growth factor alone or in combination. Pressure-volume curves with air were performed on the lungs and saturated phosphatidylcholine was measured in lung washes. Desmosine and hydroxyproline were determined in lung tissue in seven hormone-treated fetuses that displayed distensible and stable lungs similar to term lungs |volume of air at $40 \mathrm{~cm} \mathrm{II}_{2} \mathrm{O}\left(\mathrm{V}_{40}\right)>1.5$ $\mathrm{ml} / \mathrm{g}$ wet weight and at $5 \mathrm{~cm} \mathrm{H}_{2} \mathrm{O}\left(\mathrm{V}_{5}\right)>0.8 \mathrm{ml} / \mathrm{gl}$ and in seven fetuses whose lungs remained nondistensible and unstable $\left(V_{40}<0.6 \mathrm{ml} / \mathrm{g}\right.$ and $\left.V_{5}<0.4 \mathrm{ml} / \mathrm{g}\right)$. Alveolar saturated phosphatidylcholine was five times higher $(p<$ $0.001)$ in distensible than in nondistensible lungs, but attained less than $20 \%$ of term values. Desmonsine and hydroxyproline concentrations in parenchyma, pleura, and trachea of nondistensible, unstable lungs were similar to intact controls of 125 days gestation and those in distensible, stable lungs were similar to controls of 137 days gestation. Desmosine $(p<0.0001)$ and hydroxyproline $(p$ $<0.001)$ concentrations in parenchyma of distensible, stable lungs were higher than those of nondistensible, unstable lungs. We speculate that increased distensibility of the fetal lung in response to treatment with hormones is attributable in part to changes in the composition of connective tissue. (Pediatr Res 22: 339-343, 1987)
\end{abstract}

\section{Abbreviations}

SPC, saturated phosphatidylcholine

$\mathrm{RIA}$, radioimmunoassay

\footnotetext{
Distensibility and stability are prerequisites for adequate ventilatory function of the lung. There is good evidence that an increase in alveolar surfactant is causally linked to lung "maturation" i.e. the process by which the immature. noncompliant lung is transformed into a distensible and stable organ: close correlations between surface active material and lung distensibility and stability have been reported in numerous studies (1) and instillation of surface active material into immature lungs improves pulmonary ventilatory function $(2,3)$. While it is recog-

Received July 9. 1986: accepted Apri! 17, 1987.

(orrespondence Dr. J-C. Schellenterg. P'ostgraduate School of ()bstetrics and Gynaccology National Women's Hospital. Auckland. New Zealand.

Supporied by the Medical Research (ouncil of Vew /ealand the Auckland Medical Research Foundation, and ISSPHS (irant HI.O27356. Pulmonary S(OOR
}

nized that both surface forees and tissue properties determine the mechanical behavior of the adult lung (4). the relative contributions of these factors to fetal lung maturation is uncertain. During ontogenesis, collagen and elastic libers become more abundant (5-11) and changes in glycosaminoglycans occur (12) but little is known about the effects of these alterations in connective tissue structure on the mechanical properties of the lung.

Circumstantial evidence for a role of structural changes in lung maturation has been offered in several recent reports. Nlthough prenatal administration of betamethasone in rhesus monkeys leads to an increase in distensibility of the fetal lungs. changes in surface active material are inconsistent. suggesting that structural changes may predominate $(1,3-15)$. In one of these studies a slight decrease in the elastin to collagen ratio of the fetal monkey lung was found after exposure to betamethasone and it was suggested that this may signify a teratogenic effect (15). In adrenalectomized fetal sheep, infusion of cortisol but not AC "I'H increases distensibility although alveolar SPC is cqually low after either treatment (16)

The present study was designed to determine the relationship of elastin and collagen concentration to the mechanical properties of lungs in which maturation was advanced by treatment with hormones at a particular gestational age. It was postulated that the finding of changes in concentration of clastin and collagen similar to those normally occuring in compliant, near term lungs would support the hypothesis that clastin and collagen have a role in determining the properties of the mature lung.

\section{MFIHODS}

Animals. Romney-Marsh ewes were mated with Southdown rams at estrus sunchronized with raginal sponges containing $(0)$ mg medroxyprogesterone acetate (The Upjohn Company. Kalamazoo. MI). The first day of pregnancy was assumed to be the second day after withdrawal of the sponges. The estimated gestational age of the fetuses was confirmed after autopsy by radiographic examination of the ossification centers of the fetal limbs (17). On day 124 gestation (day 117 in the saline-infused animal), indwelling catheters were placed into the fetal carotid artery and jugular vein as described previously (18). Infusions were started in the evening of the day of operation (day 121 in the salineinfused animal) and the experiment terminated in the morning of day 128 by killing the fetus and the ewe with overdoses of pentobarbital. Medroxyprogesterone acetate (Depo-Provera. The Upjohn Company). 150-300) mg. was given to all ewes at the beginning of the fetal infusions to prevent premature labor. Infusions were administered alone or in combination at the following rates: cortisol $1 \mathrm{mg} / \mathrm{h}$. triiodothyronine $25 \mu \mathrm{g} / \mathrm{h}$. prolactin $1.5 \mathrm{mg} /$ day. epidermal growth factor $50 \mu \mathrm{g} /$ day and saline 
Table 1. Hormonal treatments and indices of lung maturation*

\begin{tabular}{|c|c|c|c|c|c|c|c|}
\hline Treatment & $\begin{array}{c}\text { Body wt } \\
\text { (g) }\end{array}$ & $\begin{array}{c}\text { Lung wet } \\
\text { wt (g) }\end{array}$ & $\begin{array}{c}\text { Gestational } \\
\text { age (day) }\end{array}$ & $\begin{array}{c}\text { Bone age } \\
\text { (day) }\end{array}$ & $\begin{array}{c}\mathrm{SPC} \\
(\mu \mathrm{g} / \mathrm{g})\end{array}$ & $\begin{array}{c}\mathrm{V}_{40} \\
(\mathrm{~m} \mathrm{l} / \mathrm{g})\end{array}$ & $\begin{array}{c}\mathrm{V}_{5} \\
(\mathrm{ml} / \mathrm{g})\end{array}$ \\
\hline \multicolumn{8}{|l|}{ Distensible lungs } \\
\hline $3013 C+T+P$ & 2675 & 65.0 & 126 & 123 & 128.6 & 1.56 & 1.18 \\
\hline $3075 C+T$ & 2675 & 57.3 & 126 & 126 & 220.0 & 2.23 & 1.65 \\
\hline $3095 C+T$ & 2710 & 88.2 & 128 & 129 & 133.7 & 1.61 & 1.14 \\
\hline $3195 C+E$ & 3075 & 98.8 & 125 & 128 & 79.8 & 1.60 & 0.86 \\
\hline $4044 \mathrm{~A} C+\mathrm{T}+\mathrm{P}$ & 3030 & 64.4 & 129 & 126 & 34.2 & 2.02 & 1.37 \\
\hline $4046 \mathrm{~A} C+\mathrm{T}+\mathrm{P}$ & 2260 & 57.0 & 127 & 121 & 113.7 & 2.12 & 1.41 \\
\hline $4148 \mathrm{~A} C+\mathrm{T}+\mathrm{P}$ & 2600 & 63.3 & 128 & 126 & 104.0 & 2.16 & 1.50 \\
\hline Mean & 2718 & $70.4 \dagger$ & 127.0 & 125.6 & $115.6 \ddagger$ & $1.90 \S$ & $1.30 \$$ \\
\hline SEM & 104 & 6.2 & 0.5 & 1.0 & 21.7 & 0.30 & $0.10^{\circ}$ \\
\hline \multicolumn{8}{|l|}{ Nondistensible lungs } \\
\hline $3052 \mathrm{~T}$ & 3035 & 76.6 & 128 & 129 & 10.6 & 0.43 & 0.23 \\
\hline $3074 \mathrm{~T}$ & 3130 & 80.2 & 126 & 129 & 62.1 & 0.35 & 0.23 \\
\hline $3094 \mathrm{~T}$ & 2685 & 90.4 & 125 & 124 & 10.8 & 0.31 & 0.17 \\
\hline $3158 \mathrm{C}+\mathrm{P}$ & 3595 & 103.3 & 129 & 129 & 16.2 & 0.42 & 0.19 \\
\hline $3194 C+E$ & 3125 & 107.0 & 129 & 126 & 3.0 & 0.56 & 0.23 \\
\hline $4074 \mathrm{~T}+\mathrm{P}$ & 3375 & 99.7 & 127 & 126 & 40.6 & 0.47 & 0.34 \\
\hline 4079B S & 2535 & 61.6 & 128 & 126 & 6.7 & 0.34 & 0.20 \\
\hline Mean & 3069 & 88.4 & 127.4 & 127 & 21.4 & 0.41 & 0.23 \\
\hline SEM & 139 & 6.2 & 0.6 & 0.8 & 8.2 & 0.03 & 0.02 \\
\hline
\end{tabular}

${ }^{*} \mathrm{C}$, cortisol; E, epidermal growth factor; $\mathrm{P}$, prolactin; S, saline; $\mathrm{T}$, triiodothyronine; $\mathrm{SPC}$, alveolar $\mathrm{SPC} ; \mathrm{V}_{5}$, volume of air/g lung at $5 \mathrm{~cm} \mathrm{H}_{2} \mathrm{O}$ (deflation); $\mathrm{V}_{40}$, volume of air/g lung at $40 \mathrm{~cm} \mathrm{H}_{2} \mathrm{O}$.

$+p<0.05 . \ddagger p<0.01$.

$\S p<0.001$ for differences between distensible and nondistensible lungs.

$0.5 \mathrm{ml} / \mathrm{h}$ (Table 1). Quasistatic pressure-volume curves were performed on the left lung as previously described (16). Distensibility and stability were expressed as $\mathrm{ml} / \mathrm{g}$ wet weight of lung at $40 \mathrm{~cm} \mathrm{H}_{2} \mathrm{O}\left(\mathrm{V}_{40}\right)$ and on deflation at $5 \mathrm{~cm} \mathrm{H}_{2} \mathrm{O}\left(\mathrm{V}_{5}\right)$, respectively. After completion of the pressure-volume study, the lung was rinsed three times with $0.9 \%$ saline solution using 1.5 times the volume of $\mathrm{V}_{40}$. An aliquot of the effluent of the lung was kept at $-20^{\circ} \mathrm{C}$ until further analysis for SPC.

The 14 lungs analyzed in the present investigation were also used in two larger studies $(19,20)$ designed to investigate hormonal action on lung maturation. Acceleration of lung maturation was achieved to varying degrees by different hormone infusions (see "Discussion") $(19,20)$. We chose seven "nonresponders" displaying nondistensible and unstable lungs after the infusion and seven "responders" in which lung distensibility and stability were near term values after the infusion (Table 1). Five of the seven nondistensible and unstable lungs were taken from lungs of fetuses infused with saline $(n=7)(20)$, triiodothyronine alone $(n=6)$, or triiodothyronine and prolactin $(n=5)$ all of which had nondistensible and unstable lungs similar to intact control animals of 128 days gestation (19). One nondistensible and unstable lung was selected from a group of eight fetuses infused with both cortisol and epidermal growth factor which included two "responders" and six "nonresponders" and another lung was selected from a group of six fetuses infused both with cortisol and prolactin of which one fetus displayed a partial response $\left(\mathrm{V}_{40}=1.3 \mathrm{ml} / \mathrm{g}\right)$ and five were "nonresponders." Four of the seven distensible and stable lungs were taken from a group of nine animals infused with a combination of cortisol, triiodothyronine, and prolactin all of which were "responders." The remaining three distensible and stable lungs were from fetuses infused with cortisol and triiodothyronine $(n=8$, two "responders") and from fetuses infused with cortisol and epidermal growth factor ( $n=8$, two "responders") (19). In these 14 animals the right lung was subjected to biochemical analysis after dissection into "dissected" parenchyma (removing tubular structures of $>0.1 \mathrm{~mm}$ diameter) and "nondissected" parenchyma, pleura, and trachea as described (11).
Biochemical analysis. Approximately $8 \mathrm{mg}$ of dry tissue was weighed twice on a Mettler AC 100 balance and digested twice with papain at $65^{\circ} \mathrm{C}$ for $24 \mathrm{~h}$. An aliquot was hydrolyzed with 6 $\mathrm{M} \mathrm{HCl}$ at $110^{\circ} \mathrm{C}$ for $72 \mathrm{~h}$. Collagen was measured as hydroxyproline $(11,21)$.Elastin was determined by measuring the crosslinking amino acid desmosine by RIA after cellulose chromatography and acetylation (10). Recovery of desmosine standards subjected to chromatography was between 77 and $95 \%(n=4)$. Intraassay variability of standards in the RIA was $<6 \%(n=10)$. SPC was analyzed in lung lavage fluid by the osmium tetroxide method of Mason et al. (22) as previously described (23).

Statistical analysis. General linear model procedures were performed on an IBM 4341 computer using SAS (SAS 1982, SAS Institute Inc., Cary, NC). $T$ tests were used as appropriate. Parenchyma, pleura, and trachea were analyzed separately. Variables taken into account in parenchyma were lobe (upper, middle, lower lobe), distensibility (distensible or nondistensible) and dissection (dissected or nondissected). Dissected and nondissected parenchyma was analyzed both in combination and separately. $p$ values of $>0.05$ were considered nonsignificant.

\section{RESULTS}

Mean body weight, mean lung weight, and mean bone age were slightly lower in the "responders" than in the "nonresponders" (Table 1). Elastin and collagen concentrations of distensible and stable lungs were higher than those of nondistensible lungs in each compartment, i.e. in dissected and in nondissected parenchyma of all three lobes as well as in pleura and trachea (Figs. 1 and 2). Distensible and nondistensible lungs differed most in respect to parenchymal elastin and least in respect to elastin in pleura and trachea (Figs. 1 and 2). Differences between distensible and nondistensible lungs ere more marked in dissected than in nondissected parenchyma. The difference between distensible and non-distensible lungs was greater for elastin than for collagen concentration (Figs. 1 and 2). Alveolar SPC in distensible lungs was five times higher in distensible lungs than in nondistensible lungs (Table 1) but attained less than $20 \%$ of 


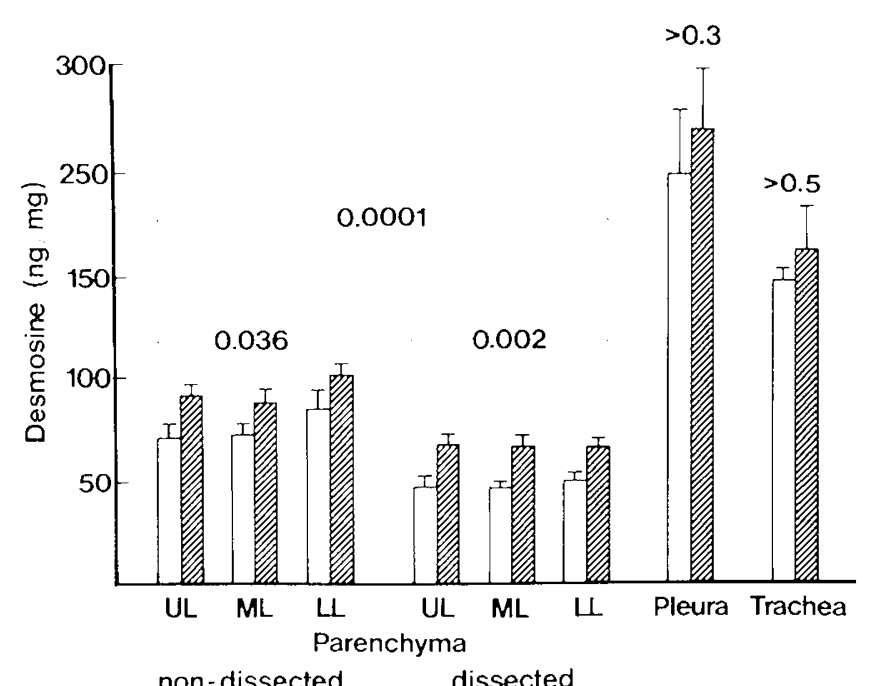

Fïg. 1. I esmosine concentrations of nondistensible, unstable lungs $\left(\mathrm{V}_{40}<0.6 \mathrm{ml} / \mathrm{g}\right.$ lung wet weight and $\mathrm{V}_{\mathrm{s}}<0.4 \mathrm{ml} / \mathrm{g}, n=7$. open hars $)$ and of distensible. stable lungs $\left(V_{40}>1.5 \mathrm{ml} / \mathrm{g}\right.$ and $\mathrm{V}_{5}>0.8 \mathrm{ml} / \mathrm{g} . n=$ 7. hatched hars) of fetuses subjected to various hormone treatments before sacrifice at 128 days of gestation. $2 \%$. upper lobe: $1 / 1$. middle lobe; I.I., lower lobe. Dissected parenchima, devoid of tubular structures of $>0.1 \mathrm{~mm}$ diameter. Numbers indicate level of statistical difference between nondistensible and distensible lungs (all three lobes combined). Brackets with probability values indicate whether dissected and nondissected parenchyma was subjected to separate or to combined statistical analysis (mean \pm SF:M).

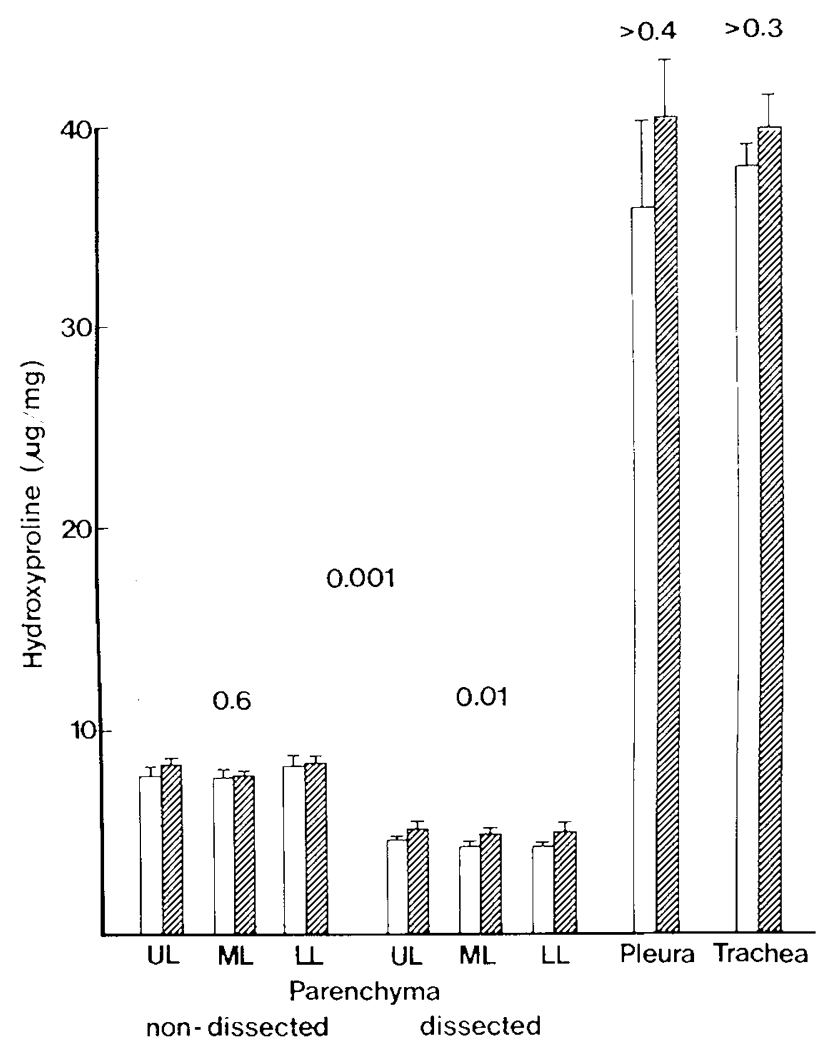

Fig. 2. Hydroxyproline concentrations of nondistensible lungs ( $n=$ 7. open bars) and of distensible lungs ( $n=7$. hatched hars) of fetuses subjected to various hormone treatments before sacrifice at 127 days of gestation. Symbols and definitions as in Figure I (mean \pm SFM). term values $(16,23)$. Despite preterm values for clastin, collagen. and alveolar SPC. $V_{4+1}$ and $V$, of distensible and stable lungs were in the range of term animals (16.23) (laable 1).

\section{DISC (ISSIO)}

The purpose of this study was to investigate the relationship between connective tissue maturation and maturation of the mechanical properties of fetal lungs. Although maturation was accelerated by various hormonal treatments the study was not designed to relate particular hormones to changes in connective tissue composition but rather to determine whether a retationship existed between composition and mechanical properties regardless of the means by which maturation was advaneed. He measured the concentrations of elastin and collagen and alveolat surfactant (SPC) in lungs of sheep fetuses in which development of distensibility and stability was advaneed by hormone tratment between davs 124 and 128 of gestation and compared them with values obtained from fetuses of similar age in which hormone treatment was without effect. (iiven the fact that all ewes were date-mated and that mean body weight. mean lung weight. and mean bone age of the "nonresponders" were slightly lower than those of the "responders" it is unlikely that crrors in determining gestation length accounted for the observed differences in the mechanical and biochemical properties of the lungs. We selected lungs that had been exposed to a number of different treatments to diminish the possibility of linding differences in elastin and collagen concentrations that were due to specilic hormonal effects which had nothing to do with the maturation of the mechanical properties of the lungs.

$A t$ around 125 days gestation. distensibility and stability of the fetal sheep lung are very low (19, 20, 24, 25). Distensibility, stability, and alveolar surfactant concentrations appear not to increase substantially until a few days before birth (24). At that time, lung maturation proceeds rapidly and in parallel with increasing fetal plasma cortisol levels suggesting a regulatory role of cortisol in ovine lung maturation (24).

The present study revealed that elastin and collagen concentrations in all compartments of nondistensible and unstable lungs, i.e. dissected and nondissected parenchyma. pleura, and trachea. were similar to those of untreated fetuses of 125 days gestation (11). In distensible and stable lungs. clastin and collagen concentrations of each compartment were similar to those of 137-day-old fetuses (11). This suggests that the changes in the collagen and elastin caused by hormonal treatment represented maturation rather than a nonphysiological response unrelated to maturation. However. this conclusion must be tentative until more detailed studies of the composition of the connective tissue. including the proteoglycan matrix, have been made.

Although the levels of afreolar SPC, the major constituent of surfactant in fetal sheep lung (26). were tive times higher in distensible and stable lungs than in nondistensible and unstable lungs, they were still at least six times lower than in control animals (16. 23). Similar levels of alveolar SPC to those in distensible and stable lungs of the present study were found both in nondistensible and unstable lungs of adrenalectomized fetal sheep infused with $\mathrm{ACTH}$ at term and in lungs of cortisol-infused adrenalectomized fetuses which were moderately distensible (mean $\mathrm{V}_{40}=1.2 \mathrm{ml} / \mathrm{g}$ ) but unstable (16). This lack of correlation between distensibility and stability and alveolar SPC levels in lungs exposed to different treatments points to structural differences causing differences in the mechanical properties of the lung. The present observation of increasing elastin and collagen concentrations being associated with maturation of the mechanical properties of the lung offers further support to this contention. Unlike surfactant, which can be added or removed from lung $(2,27)$. connective tissue is an integral part of the organ; accordingly, a direct relationship between connective tissue maturation and the mechanical properties of the lung is difficult to establish. 
Pulmonary distensibility and stability determined by singleloop quasistatic pressure-volume curves in the group of "responders" was similar to values obtained in normal term fetuses $(16,23,24)$ although elastin and collagen concentrations and alveolar SPC levels were substantially lower. This raises the question of how well these pressure-volume curves define pulmonary maturity and whether the lungs of the "responders" are mechanically less mature than normal term lungs in respect to criteria that we did not evaluate such as dynamic compliance and the behavior in response to repeated inflations.

The several-fold lower surfactant levels in lung washes of "responders" than in washes from normal term lungs is unlikely to be due solely to less surfactant being required to cover the airspace walls in view of the finding that alveolar surface area increases less than $50 \%$ between days 120 and 141 gestation (28) Higher intraalveolar reserves of surfactant (situated in the subphase) and increased washout of intracellular SPC when rinsing with saline may contribute to the larger quantities of alveolar SPC measured in term lungs.

Because pressure-volume curves give little information on events at the alveolar level we can only speculate what the underlying mechanism of increasing distensibility and stability in the lungs of "responders" might be. In lungs of adult rabbits inflated with air and fixed intravascularly (thereby preserving as much as possible the air-tissue interface), morphometric and morphological analysis suggested that changes in lung volume are associated with recruitment/derecruitment of air spaces, balloon-like changes in alveolar size, simultaneous changes of alveolar size and shape (accompanied by septal pleating) and crumpling of the alveolar surface (29). In a similar study, the same authors suggested a model for the lung consisting of a flimsy meshwork subjected mainly to surface forces suspended within a wider-meshed fibrous skeleton that is stabilized by interdependence (27). This model offers a compromise between the bubble-on-a-tube model (30) recognizing surface forces only and the interdependence model stressing the existence of a framework formed by the walls separating individual airspaces (31). Kitterman et al. (24) published microphotographs showing that distensible lungs of fetal sheep at term have larger airspaces than nondistensible term lungs fixed intratracheally at the same pressure (thereby abolishing surface forces) suggesting that the walls of the airspaces become more distensible during maturation. Mitzner et al. (32) concluded from their morphometric studies in lungs of fetal monkeys exposed to betamethasone (see below) that some form of recruitment increased distensiblity of these lungs. We speculate that increasing elastin and collagen concentrations may reflect increased subdivision of airspaces and thus the creation of more recruitable airspaces $(8,28)$, increasing length of elastin and collagen fibers which coil up at low lung volumes and permit more stretching of the airspace walls when the lung is inflated (27) and finally, a stronger structural meshwork that helps to prevent the lung from collapsing (33).

Our observations differ from those of Johnson et al. (13), Mitzner et al. (14), and Beck et al. (15) in several ways. While we found an increase in both SPC and the elastin/collagen ratio (which is one of the salient features of connective tissue development of the fetal lung $(1,10,11)$ (Figs. 1 and 2), Johnson and coworkers (13-15) found no evidence of changes in surfactant and a slight decrease in the elastin/collagen ratio in distensible lungs of fetal rhesus monkeys that had been exposed to betamethasone. They suggested that the latter finding signifies pathological development, and indeed, multiple developmental anomalies including retarded growth of the lungs and reduced alveolar stability were found in monkeys that had been exposed to a similar regimen of betamethasone (34). There could be several reasons for the discrepancies between their findings in monkeys and our results in sheep. None of our fetuses was exposed to glucocorticoids alone, but all received triiodothyronine, prolactin or EGF in addition (Table 1). The monkeys were exposed to betamethasone at an earlier stage of lung development than our sheep fetuses. Bunton and Plopper (35) have shown that glucocorticoids have age-specific effects on fetal lung development in the monkey but their animals displayed apparently normal accelerated morphological development of the lungs when glucocorticoids were given at a gestational age similar to that in the study of Beck et al. (15).

We conclude that, under the conditions of these experiments, altered mechanical properties of the fetal lungs are associated with changes in the concentrations of elastin and collagen that are in the same direction as those occurring during normal maturation. This finding suggests that these components of connective tissue have a significant role in the functional maturation of the lung.

Acknowledgement. The authors thank Alistair W. Stewart, Department of Community Health, University of Auckland, for help with statistics.

\section{REFERENCES}

1. Schellenberg JC 1986 The development of connective tissue and its role in pulmonary mechanics. In: Johnston B. Gluckman PD (eds) Respiratory Control and Lung Development in the Fetus and Newborn. Reproductive and Perinatal Medicine, Vol. 3. Perinatology Press, Ithaca NY, pp 3-62

2. Morley CJ 1984 Surfactant treatment for respiratory distress syndrome: a review. J Royal Soc Med 77:788-792

3. Enhorning G, Shennan A, Possmeyer F, Dunn M, Chen CP, Milligan J 1985 Prevention of neonatal respiratory distress syndrome by tracheal instillation of surfactant: a randomized clinical trial. Pediatrics 76:145-153

4. Hoppin FG, Hildebrandt J 1977 Mechanical properties of the lung. In: West JB (ed) Bioengineering Aspects of the lung. Lung Biology in Health and Disease, Vol. 3. Marcel Dekker, New York, pp 83-162

5. Collet AJ, Des Biens G 1974 Fine structure of myogenesis and elastogenesis in the developing rat lung. Anat Rec 179:343-360

6. Loosli CG, Potter EL 1959 Pre- and postnatal development of the respiratory portion of the human lung. Am Rev Respir Dis 80:5-23

7. Bradley KH, McConnell-Breul S, Crystal RG 1974 Collagen in the human lung. Quantitation of rates of synthesis and partial characterisation of composition. J Biol Chem 249:2674-2683

8. Fukuda Y, Ferrans VJ, Crystal RG 1983 The development of alveolar septa in fetal sheep lung. An ultrastructural and immunohistochemical study. Am J Anat 167:405-439

9. Keeley FW, Fagan DG, Webster SI 1977 Quantity and character of elastin in developing human lung parenchymal tissues of normal infants and infants with respiratory distress syndrome. J Lab Clin Med 90:981-989

10. Schellenberg JC, Liggins GC, Stewart AW 1987 Growth, elastin concentration and collagen concentration of perinatal rat lung: effects of dexamethasone. Pediatr Res 21:603-607

11. Schellenberg JC, Liggins GC 1987 Elastin and collagen in fetal sheep lung. I. Ontogenesis. Pediatr Res 22:335-338

12. Horwitz AL, Crystal RG 1975 Content and synthesis of glycosaminoglycans in the developing lung. J Clin Invest 56:1313-1318

13. Johnson JWC, Mitzner W, London WT, Palmer AE, Scott R, Kearney K 1978 Glucocorticoids and the rhesus fetal lung. Am J Obstet Gynecol 130:905916

14. Mitzner W, Johnson JWC, Scott R, London WT, Palmer AE 1979 Effect of betamethasone on pressure-volume relationship of fetal rhesus monkey lung. J Appl Physiol 47:377-382

15. Beck JC, Mitzner W, Johnson JWC. Hutchins GM, Foidart GM. Palmer AE, Scott R 1981 Betamethasone and the rhesus fetus: effect on lung morphometry and connective tissue. Pediatr Res 15:235-240

16. Liggins GC, Schellenberg JC, Finberg K, Kitterman JA, Lee CH 1985 The effects of $\mathrm{ACTH}_{1-24}$ or cortisol on pulmonary maturation in the adrenalectomized ovine fetus. J Dev Physiol 7:105-111

17. Richardson C, Herbert CN, Terlecki S 1976 Estimation of the developmental age of the ovine fetus and lamb. Vet Rec 99:22-26

18. Nathanielsz PW, Abel MH, Bass FG, Krane EJ, Thomas AL, Liggins GC 1978 Pituitary stalk-section and some of its effects on endocrine function in the fetal lamb. Q J Exp Physiol 63:211-219

19. Schellenberg JC, Liggins GC, Manzai M 1985 Synergistic effects of cortisol, tri-iodothyronine, prolactin and adrenaline on lung maturation in the ovine fetus. Proc Endocrine Soc of Aust 28(suppl 2):33

20. Liggins GC, Schellenberg JC, Manzai M, Court DJ 1985 Synergistic effects of thyrotropin releasing hormone (TRH) and cortisol on lung maturation in the ovine fetus. Proc Endocrine Soc Aust 28(suppl 2):32

21. Stegemann H, Stalder K 1967 Determination of hydroxyproline. Clin Chim Acta $18: 267-273$

22. Mason RJ, Nellenbogen J, Clements JA 1976 Isolation of disaturated phosphatidylcholine with osmium tetroxide. J Lipid Res 17:281-284

23. Liggins GC, Kitterman JA, Campos GA, Clements JA, Forster CS, Lee CH, Creasy RK 1981 Pulmonary maturation in the hypophysectomized ovine fetus. Differential response to adrenocorticotrophin and cortisol. J Dev Physiol 3:1-14 
24. Kitterman JA I iggins (iC Campos (iA C 'lements JA Forster ( S L Lee CH Creasy RK 1981 Prepartum maturation of the lung in fetal sheep: relation to cortisol. J Appl Physiol 52:384-390)

25. Brumley (iW, Chernick V. Hodsen WA. Normand (D. Fenner A. Avery MF 1967 Correlations of mechanical stability. morphology, pulmonary surfactant, and phospholipid content in the developing lamb lung. J (Cin Invest $46: 86.3-873$

26. Benson BJ, Kitterman JA. Clements JA. Mescher EJ. Tooley WH 1983 Changes in phospholipid composition of lung surfactant during development in the fetal lamb. Biochim Biophys Acta 75,3:83-88

27. Bachofen H, (iehr P. Weibel I:R 1979 Alterations of mechanical properties and morphology in excised rabbit lungs rinsed with a detergent. J Appl Physiol 47:10()2-1010

28. Aleorn IX; Adamson IM. Maloney Jt: Robinson PM 1981 A morphologic and morphometric analysis of fetal lung development in the sheep. Anat $\operatorname{Rec} 201: 655-6667$

29. (iil J. Bachofen H. (ichr P. Weitxl I:R 1979) Alveolar volume-surface area relation in air- and saline-filled lungs fixed by vascular pertusion. I Appl Physiol 47:990-1001

30. Mead J 1960 The mechanical properties of alveoli. Am Rev Resprir 1) is $81: 7.39$ 742

31. Mead J, Takishima T. I. cith 1) 1970) Stress distribution in lungs: a model of pulmonars clasticity. J Appl Phssiol $28: 596-608$

32. Mitzner $W$ Johnson JWC Beck J Iondon W. Sly I) 1982 Influenee of betamethasone on the development of mechanical propertics in the ketal rhesus monkey lung. Am Rev Respir 1) is 125:23.3-238

33. Fung $Y(1975$ Does the surface-tension make the lung mberently unstable"? (irc Res 37:497-50)

34. Johnson JW( Mitzner W Beck JC I oidon W'l Sly D I I e P. Khouram VA. Cavalieri RI. 1981 1.ong-term offects of betamethasone on fital deveopment. Am J Ohstet (ivnecol 1+1:105:-1064

35. Bunton TH, Plopper ( $($; 1984 Triamcinolone-induced structural alterations in the development of the lung of the fetal rhesus macalque. Am I Obstet (innecol 148:203-215 